\title{
Environmental interventions based on the Health Belief Model and the Ecological-social model in the continuation of consumption of rice, free from toxic metals
}

\author{
Leili Shafiei $^{1}$, Parvaneh Taymoori ${ }^{2,3}$, Afshin Maleki $^{1}$, Kourosh Sayehmiri $^{4}$
}

${ }^{1}$ Environmental Health Research Center, Kurdistan University of Medical Sciences, Sanandaj, Iran

${ }^{2}$ Social Determinants of Health Research Center, Kurdistan University of Medical Sciences, Sanandaj, Iran

${ }^{3}$ Department of Public Health, Faculty of Health, Kurdistan University of Medical Sciences, Sanandaj, Iran

${ }^{4}$ Psychosocial Injuries Research Center, Biostatistics department, Ilam University of Medical Sciences, Ilam, Iran

\section{Type of article: Original}

\begin{abstract}
Background and aim: Continuation of healthy nutritional behaviors is one of the important factors in effectiveness of educational intervention programs. The aim of this research is to compare the Health Belief Model and the Ecological-social model in reducing consumption of rice contaminated with toxic metals after completion of environmental intervention and continuation of consumption of healthy rice.

Methods: This research was the implementation of a six-month randomized controlled trial interventional program in two groups' interventions along with a control group, with 80 people for each group totally, amounting to 240 women, between 18 and 50 years of age in Ilam, Iran in 2014. The questionnaires of the three groups consisted of demographic information, knowledge, the constructs of the models, performance of rice consumption. Friedman test and repeated measures used for data analysis with SPSS (version 20), and confidence interval of $95 \%$ were considered.

Results: The results of the Friedman test indicated a significant increase in the number of women consuming healthy rice over six months after intervention in both intervention groups $(\mathrm{p}<0.001)$. Women in the ECO group consumed healthy rice $27.5 \%$ more than the HBM group $(\mathrm{p}<0.001)$. The results of repeated measures analysis of variance suggested greater improvement in the consumption of healthy rice in the ECO group in comparison with the HBM group over six months after intervention $(\mathrm{p}<0.05)$.

Conclusions: Both educational environmental intervention methods caused the altered diet of people regarding consumption of healthy rice over six months after the intervention. Increased social support also probably had a more effective role in continuation of healthy diet among the people.
\end{abstract}

Keywords: Environmental intervention, Toxic metals, Rice, Health belief model, Ecological-social model

\section{Introduction}

Presence of toxic metals such as lead, arsenic and cadmium in consumer rice of Iran has been proven (1-3). Long term usage of rice contaminated with toxic metals, causes cancers and damage to the liver, lungs and nervous system (4). Conducting environmental interventions to enhance people's knowledge in the selection of healthy foods has an effective role in solving this problem $(5,6)$. One of the behavioral models which is effective for people to follow a healthy diet is the Health Belief Model (HBM) $(7,8)$. In this model, attention to the constructs of "perceived sensitivity", "perceived seriousness", "perceived benefits", "perceived barriers" and "self-efficacy" for not consuming unhealthy foods is essential (9). However, in this model the role of interpersonal factors has not been considered (10). One of the successful behavioral models that considers individual, social and environmental factors in adherence of people to healthy diet is the ecological-social model (ECO) (11, 12). ECO environmental intervention develops improvement and sustainability of healthy habits in people $(13,14)$. This model examines the effect of social support and social networks in changing behavior at an interpersonal level (15). Lack of social

\section{Corresponding author:}

Parvaneh Taymoori. Tel: +98-9183737303, Fax: +98-871-6131468, E-mail: Parvaneh.tay@gmail

Received: June 25, 2017, Accepted: August 22, 2017, Published: January 2018

iThenticate screening: July 22, 2017, English editing: December 13, 2017, Quality control: December 15, 2017

This article has been reviewed / commented by three experts

(C) 2018 The Authors. This is an open access article under the terms of the Creative Commons Attribution-NonCommercialNoDerivs License, which permits use and distribution in any medium, provided the original work is properly cited, the use is non-commercial and no modifications or adaptations are made. 
support is a barrier against changing food behaviors, weight loss, healthy nutrition, and healthy lifestyle (16, 17). Using the worksite is a unique option for involving people in preventive programs of health (12, 18). Numerous studies have proven the effective role of social support in enhancing consumption of fruits and vegetables (12, 19) and behaviors for decreasing consumption of fat (20). However, to date, no study has been performed on the investigation of the effect of the ECO model over the HBM model in encouraging people to follow a healthy diet and continue it. On the other hand, it was assumed that the development of the social network would have an effective role in consumption of rice free from toxic metals and continuation of its consumption, in comparison with an HBM. Testing this hypothesis presents some solutions for setting the ground for enhancing the efficiency of environmental interventions and their effect on the continuation of healthy behaviors. Because of the important role of women in families and the availability of local rice for households (21), the site of implementation of this semiexperimental research was in Ilam in 2014. The hypotheses of the study were: 1) in the HBM and ECO groups, there is a significant difference of knowledge, the constructs of the models and performance between the period before and after the intervention and continuation within three and six months after completion of the educational intervention 2) there is a difference between before and after the intervention and continuation within three and six months after completion of the educational intervention in HBM, ECO and control groups, and this difference in continuation in increasing the consumption of local rice and decreasing consumption of Imported rice is greater in the ECO group when compared with the HBM and control groups.

\section{Material and Methods}

\subsection{Research design and setting}

This research was an environmental intervention program based on HBM and ECO models for enhancing consumption of rice free from toxic metals, and continuation of its consumption in women. All the participants signed a consent form before taking part in the training. Inclusion criteria were women between ages 18 and 50 years with the responsibility of cooking in Ilam. Exclusion criteria was dissatisfaction with participating in training sessions. The probabilistic value of the knowledge level of women about contamination of consumed rice with toxic metals was obtained as $30 \%$ by pretesting 30 people of those who had the characteristics of the target population using the plan's questionnaire. In this research, $\alpha$ was considered to be 0.05 , while $\beta$ was assumed to be $20 \%$. Assuming the minimum enhancement of the expected knowledge after the intervention as $20 \%$, the number of samples was obtained as 80 people for each group (two intervention groups and one control group), amounting to 240 people. The samples in the HBM and control groups were selected from 13 health care centers in Ilam city, 8 clinics in a simple random form, and in each center, two 10-household clusters (one cluster as the HBM group and another cluster as the control group) were chosen randomly. In the healthcare centers, using the following number of households, the cluster heads were chosen, and after referring to the cluster heads in presenting some explanations about the plan, in regard to consent of the participant in the training sessions, the questionnaire was completed as preliminary evaluation. In the ECO group, out of 12 organizations in Ilam city, 6 organizations were chosen randomly and with participation in the organizations and presenting explanations about the plan, following the approval of employed women to participate in the training sessions, the questionnaire was completed as the preliminary evaluation. The Water and Food Research Center of Kurdistan University of Medical Sciences approved the protocol of the plan's interventional program with Grant number 14/36500.

\subsection{Data collection}

Data collection was performed across four stages: before the intervention (December 2014), after the six-month intervention (June 2015), three months after completion of the intervention (September 2015) and six months after completion of the intervention (December 2015). The measured performance included change in the frequency of consumption of local rice, imported rice and mixed rice and change in the method of cooking from Kateh to Pilaw.

\subsection{Instruments}

In the HBM model, the study's instrument included a researcher-made questionnaire consisting of 4 sections and 36 items. The first section included demographic information (age, level of education and marital status). Other sections included knowledge, the constructs of HBM model and performance of rice consumption. In this section, "knowledge" of toxic metals was questioned. Correct responses were given one score, while wrong responses received no score. The range of score was 0 to 7 . More score showed high knowledge. The total score was obtained by calculating the mean value. The validity obtained from this section by test-retest method was obtained as $\mathrm{K}=0.84$. In the section of the constructs of the HBM model, the "perceived sensitivity" construct was measured regarding the probability of people suffering from diseases caused by consumption of rice contaminated with toxic metals. The range of score was 2 to 10 . More score indicated high perceived sensitivity. Measurement of the "perceived 
seriousness" construct was related to the fear from diseases and complications caused by consumption of rice contaminated with toxic metals (especially some types of cancer). The range of score was 5 to 25 . More score indicated high perceived seriousness. In evaluation of the construct "perceived benefits", regarding the benefits resulting from rice free from toxic metals such as prevention from getting cancer were measured. The range of score was 5 to 25 . More score showed high perceived benefits. In the section of "perceived barriers", the barriers to consuming rice free from toxic metals such as the high price of rice free from toxic metals, lack of knowledge about the diseases caused by consumption of rice contaminated with toxic metals, difficult of cooking rice free from toxic metals, pest-proneness of such rice, and not being able to distinguish contaminated rice from healthy rice were evaluated. The range of score was 6 to 30. More score indicated high perceived barriers. In the section of "selfefficacy", the ability of people to consume rice free from toxic metals was assessed. Items such as "the ability of people not consume rice contaminated with toxic metals, consumption of rice free from toxic metals despite the desire of family members to consume rice contaminated with toxic metals, ability in saving costs for purchasing rice free from toxic metals, ability in keeping rice free from toxic metals to prevent blight" were used. Range of score was 4 to 20. More score showed high self-efficacy. A five-option Likert scale (completely correct $=5$ to completely wrong =1) was used for measuring the constructs of the HBM model. Calculation of the mean value was employed for determining the scores of these constructs. The Cronbach's alpha coefficient obtained for the constructs of perceived sensitivity, perceived seriousness, perceived benefits, perceived barriers, and self-efficacy was $0.72,0.75$, $0.8,0.81$, and 0.79 , respectively. In the section of "performance of rice consumption", the frequency of the rice consumption per week and the manner of rice cooking were evaluated. The type of consumed rice was considered as "consumption of local rice, consumption of imported rice, and consumption of mixed rice (a mixture of local and imported rice)" across three options (did not consume in the previous week, consumes 1-3 times per week, and consumes 4-7 times per week). In the section of the cooking manner, it was determined as cooking in the Pilaw method or cooking in the Kateh method. The validity obtained for this section by test-retest method was $\mathrm{K}=0.85$. In the ECO model, a researcher-made questionnaire was used consisting of 26 items across 4 sections including demographic information, knowledge, social support construct, and performance of rice consumption. In the construct "social support", the people's social network support was determined by the individual support of mother, father, sister, brother, spouse, children, friends, colleagues, neighbors, and relatives. The response of the items was determined to be in a three-option format (often $=2$ to never $=0$ ). The range of score was 0 to 216 . More score indicated high social support. The score of this construct was evaluated by calculating the mean value as the social support score. The Cronbach's alpha coefficient obtained for the social support section was 0.88 . The sections of demographic characteristics, knowledge, and rice consumption performance in the ECO group were evaluated by the same procedure for the HBM group.

\subsection{Planning of Environmental Intervention}

The environmental training sessions were held to enhance the women's knowledge regarding environmental contaminants including toxic metals and a selection of rice free from toxic metals in the food plan of the household. The training course lasted 6 months in the two intervention groups of HBM and ECO (Table 1). These 45-60-minute training sessions involved a lecture, slides, role-play and educational CDs. For the women in the control group, no training session or telephone consultation was provided. At the end of each training session, the participants received pamphlets and reminder cards to take part in the next session. The sites of holding the training sessions were clinics and organizations for the HBM and ECO group, respectively. In these sessions, Ilam local rice was introduced to the participants as the rice free from toxic metals (according to the experiments on the samples of Ilam local rice, showing absence of any toxic metal in this rice, and lack of existence of industrial factories around the rice fields of Ilam). On the other hand, due to confirmation of contamination of local and imported rice with toxic metals (1-3), it was recommended that the households avoid consuming these types of rice or minimize their consumption. The participants took part in question and answer sessions for 15-30 minutes after each session about the content of the training sessions. The training sessions in the HBM group were held individually, while in the ECO group, training was given to participants as a group, to develop a social network. The women in these groups were encouraged to consume local rice, with an increase of knowledge by way of introducing the disease caused by consumption of rice contaminated with toxic metals. They received the social support of family members, friends, and colleagues in changing their diet and consuming rice free from toxic metals during the intervention period. In addition to presenting the essential training in the groups, telephone consultations were also provided for the participants with an interval of one week and coordination with the person two days ahead. The aim of performing telephone consultations was to emphasize the consumption of healthy rice and to overcome the barriers to consuming rice contaminated with toxic metals and enhance self-efficacy. In the ECO group, due to existence of facilities at the worksite, group cooking was practiced. The solutions to decreasing consumption of rice 
contaminated with toxic metals in the HBM and ECO groups were: decreasing consumption of imported rice and substituting it with local rice, reducing rice consumption in the diet, mixing local rice with imported rice and increasing the share of local rice in relation with imported rice, cooking with a mixture of cereals and beans by increasing the portion of cereals and beans in relation with rice, and cooking foods without rice in the diet of households. In both intervention groups, rice cooked in the Pilaw method was introduced as the healthy cooking approach due to reduction of its toxic metals (22). The incentive for consumption of local rice and recurrent presence in the training sessions was the delivery of a $3-\mathrm{kg}$ local rice package as a gift to each of the participants. Also, some individual consultation sessions were held for the women in the HBM group to enhance their selfefficacy, while for the ECO group, sessions were held to enhance social support and follow up consumption of local rice and cooking in Pilaw method.

\subsection{Data Entry and Statistical Analysis}

After feeding the data into IBMC SPSSC Statistics version 20 (IBMC Corp., Armonk, NY, USA), KolmogorovSmirnov test was used to evaluate the normality of the knowledge data as well as the constructs of HBM and ECO models. For descriptive analysis of the variables, the descriptive statistics including frequency, mean, and confidence interval of $95 \%$ were considered. In the section of the performance of women in terms of the type of consumed rice, consumption of local rice, imported rice and mixed rice, and the method of rice cooking were evaluated. To evaluate the changes in knowledge, the model's constructs, and the performance of rice consumption in the three groups (HBM, ECO and control) before the intervention until the period after the intervention, three months following completion of the intervention, and six months following completion of the intervention, as the data were not normal, Friedman test was employed. Repeated measures analysis of variance was used to compare consumption of local rice, imported rice, and mixed rice in the three groups before the intervention, immediately after the intervention, three months after the intervention and finally, six months after the intervention.

Table 1. Different constructs and objectives of the training sessions of two intervention groups

\begin{tabular}{|l|l|}
\hline Constructs & Objectives of the training sessions \\
\hline Knowledge & $\begin{array}{l}\text { Introducing of toxic metals, the toxic metals contaminating the consumed rice of households, the } \\
\text { ways through which toxic metals enter the body, the diseases caused by consumption of rice } \\
\text { contaminated with toxic metals and the solutions to decreasing the toxic metals in the body were } \\
\text { stated }\end{array}$ \\
\hline $\begin{array}{l}\text { Perceived } \\
\text { sensitivity }\end{array}$ & $\begin{array}{l}\text { Enhancing the sensitivity of people to the diseases caused by consumption of rice contaminated } \\
\text { with toxic metals }\end{array}$ \\
\hline $\begin{array}{l}\text { Perceived } \\
\text { seriousness }\end{array}$ & $\begin{array}{l}\text { Increasing the perceived seriousness of people about getting diseases caused by consumption of } \\
\text { rice contaminated with toxic metals }\end{array}$ \\
\hline $\begin{array}{l}\text { Perceived } \\
\text { berceived }\end{array}$ & $\begin{array}{l}\text { Increasing the benefits resulting from consuming rice free from toxic metals and developing the } \\
\text { benefits of reducing the consumption of rice in the household's food basket }\end{array}$ \\
\hline $\begin{array}{l}\text { Social } \\
\text { support }\end{array}$ & $\begin{array}{l}\text { Overcoming the individual and environmental barriers to consuming rice free from toxic metals } \\
\text { and some explanations about how these barriers can be overcome } \\
\text { about the contamination of consumed rice with toxic metals and the manner of cooking local rice; } \\
\text { developing social network by adding mother, sister, friends, colleagues, and relatives in virtual } \\
\text { spaces such as Viber, WhatsApp and Telegram }\end{array}$ \\
\hline Self-efficacy & $\begin{array}{l}\text { Enhancing the ability of women regarding the correct cooking manner of rice free from toxic } \\
\text { metals; enhance their ability in proper preservation of rice free from toxic metals to prevent blight; } \\
\text { increasing their ability in cooking rice free from toxic metals in the food plan despite the desire of } \\
\text { family members and economic management in the household's expenditures to purchase rice free } \\
\text { from toxic metals }\end{array}$ \\
\hline
\end{tabular}

\section{Results}

The age classes of women participating in the health belief group, ecological-social group, and control group are provided in Table 2. In the HBM group, the mean score of participants' age was $36.79 \pm 8$, in the ECO group it was $33.76 \pm 5.24$, and in the control group it was 36.4 \pm . In the HBM group, 50\% of women had a high school diploma, while in the ECO group, $95 \%$ of women had academic education, and in the control group, $45 \%$ of women had only a high school diploma. The three groups were not significantly different in terms of marital status. Table 3 indicates that the average knowledge of toxic metals had a significant increase in the HBM group following the intervention, 
and three and six months following completion of the educational intervention, had a slight descending trend. The constructs of perceived sensitivity, perceived seriousness, perceived benefits, and self-efficacy had a significant increase when compared with the period before the intervention, and shows a descending trend after three months following completion of the intervention, and then until six months, showed a significant growth. The perceived barriers after the intervention, when compared with the period before the intervention, three and six months following completion of the intervention showed a significant descending trend $(\mathrm{p}<0.001)$. In the ECO group, a significant growth was observed in the participants' knowledge about contamination of consumed rice with toxic metals and the effects caused by their consumption on the body, and social support after the intervention when compared with the period before the intervention. Next, this trend showed a decrease following three months after the training intervention, and then after six months following completion of the intervention, it showed an increase. These changes were significant across the four measurement times $(\mathrm{p}<0.001)$, as shown in Table 4 .

Table 2. The demographic characteristics of the three groups HBM, ECO and control

\begin{tabular}{|l|l|l|l|l|l|l|l|}
\hline \multirow{2}{*}{ Demographic characteristics } & \multicolumn{2}{|c|}{ HBM } & \multicolumn{2}{|l|}{ ECO } & \multicolumn{2}{l|}{ CON } \\
\cline { 3 - 8 } \multicolumn{2}{|l|}{} & $\mathrm{n}$ & $\%$ & $\mathrm{n}$ & $\%$ & $\mathrm{n}$ & $\%$ \\
\hline \multirow{3}{*}{ Age (year) } & $18-29$ & 17 & 21.2 & 15 & 18.8 & 20 & 25 \\
\cline { 2 - 8 } & $30-39$ & 31 & 38.8 & 56 & 70 & 28 & 35 \\
\cline { 2 - 8 } & $40-50$ & 32 & 40 & 9 & 11.2 & 32 & 40 \\
\hline \multirow{3}{*}{ Education level } & Under high school diploma & 40 & 50 & 0 & 0 & 36 & 45 \\
\cline { 2 - 8 } & High school diploma & 24 & 30 & 4 & 5 & 20 & 25 \\
\cline { 2 - 8 } & Academic & 16 & 20 & 76 & 95 & 24 & 30 \\
\hline \multirow{2}{*}{ Marital status } & Married & 11 & 13.8 & 16 & 20 & 7 & 8.8 \\
\cline { 2 - 8 } & Other (single, widowed, divorced) & 69 & 86.2 & 64 & 80 & 73 & 91.2 \\
\hline
\end{tabular}

Table 3. The knowledge and constructs of two HBM and control groups before, immediately after, three months, and six months after the intervention

\begin{tabular}{|c|c|c|c|c|c|c|c|c|c|c|}
\hline \multirow[t]{2}{*}{ Construct } & \multicolumn{4}{|c|}{ HBM; Mean (SD) } & \multirow[t]{2}{*}{ p-value } & \multicolumn{4}{|c|}{ CON; Mean (SD) } & \multirow{2}{*}{\begin{tabular}{|l}
$\mathrm{p}-$ \\
value
\end{tabular}} \\
\hline & BI & $\mathrm{AI}$ & $3 \mathrm{M}$ & $6 \mathrm{M}$ & & BI & $\mathrm{AI}$ & $3 \mathrm{M}$ & $6 \mathrm{M}$ & \\
\hline Knowledge & $1.18(2.45)$ & $6.95(0.21)$ & $6.84(0.42)$ & $6.75(1.11)$ & 0.000 & $0.35(1.45)$ & $0.98(2.21)$ & $0.48(1.69)$ & $0.46(1.66)$ & 0.043 \\
\hline $\begin{array}{l}\text { Perceived } \\
\text { susceptibility }\end{array}$ & $7.72(1.57)$ & $9.07(0.96)$ & $8.86(0.97)$ & $8.99(1.3)$ & 0.000 & $8.21(1.21)$ & $8.08(1.64)$ & $8.11(1.19)$ & $7.16(2.04)$ & 0.001 \\
\hline $\begin{array}{l}\text { Perceived } \\
\text { seriousness }\end{array}$ & $19.93(3.46)$ & $22.71(2.17)$ & $21.9(2.23)$ & $22.51(2.36)$ & 0.000 & $20.94(2.91)$ & $\begin{array}{l}20.86 \\
(3.25)\end{array}$ & $20.36(3)$ & $\begin{array}{l}19.01 \\
(4.69)\end{array}$ & 0.134 \\
\hline $\begin{array}{l}\text { Perceived } \\
\text { benefits }\end{array}$ & $20.65(3.43)$ & $22.96(2.1)$ & $22.01(2.34)$ & $23(2.25)$ & 0.000 & $20.86(2.85)$ & $\begin{array}{l}21.06 \\
(3.19)\end{array}$ & $21.13(2.77)$ & $\begin{array}{l}20.58 \\
(4.13)\end{array}$ & 0.907 \\
\hline $\begin{array}{l}\text { Perceived } \\
\text { barriers }\end{array}$ & $25.18(3.84)$ & $21.25(2.5)$ & $19.95(3.99)$ & $17.52(4)$ & 0.000 & $25.03(3.96)$ & $\begin{array}{l}26.21 \\
(2.77)\end{array}$ & $24.8(3.68)$ & $25.4(3.37)$ & 0.277 \\
\hline Self-efficacy & $11.19(3.55)$ & $14.75(3.74)$ & $12.58(4.84)$ & $13.35(5.16)$ & 0.000 & $11.84(3.8)$ & $\begin{array}{l}10.74 \\
(3.92)\end{array}$ & $9.89(3.26)$ & $9.6(3.09)$ & 0.000 \\
\hline
\end{tabular}

BI: Before intervention, AI: After intervention, 3M: Three months, 6M: Six months

Table 4. The knowledge and constructs of two ECO and control groups before, immediately after, three months, and six months after the intervention

\begin{tabular}{|c|c|c|c|c|c|c|c|c|c|c|}
\hline \multirow[t]{2}{*}{ Construct } & \multicolumn{4}{|c|}{ ECO; Mean (SD) } & \multirow{2}{*}{$\begin{array}{l}\text { p- } \\
\text { value }\end{array}$} & \multicolumn{4}{|c|}{ CON; Mean (SD) } & \multirow{2}{*}{$\begin{array}{l}\text { p- } \\
\text { value }\end{array}$} \\
\hline & BI & AI & $3 \mathrm{M}$ & $6 \mathrm{M}$ & & BI & AI & $3 \mathrm{M}$ & $6 \mathrm{M}$ & \\
\hline Knowledge & $4.73(2.68)$ & $6.86(0.44)$ & $6.8(0.53)$ & $6.85(0.39)$ & 0.000 & $0.35(1.45)$ & $0.98(2.21)$ & $0.48(1.69)$ & $0.46(1.66)$ & 0.043 \\
\hline Social support & $64(25.04)$ & $117(28.12)$ & $114.79(24.24)$ & $118.56(23.2)$ & 0.000 & $78.01(15.76)$ & $63.99(9.6)$ & $61.84(9.27)$ & $58.98(8.98)$ & 0.000 \\
\hline
\end{tabular}

BI: Before intervention, AI: After intervention, 3M: Three months, 6M: Six months

In the HBM group, $2.5 \%$ of women (sum of frequency of 1-3 times per week and 4-7 times per week) before the intervention, $6.2 \%$ after the intervention, $13.7 \%$ three months following completion, and $18.7 \%$ six months following completion of the intervention consumed local rice. In the ECO group, 12.5\% (sum of frequency of 1-3 times per week and $4-7$ times per week) before, $33.7 \%$ after, $37.5 \%$ three months after, and $43.7 \%$ six months after the intervention, consumed local rice. This increase in the consumption of local rice was significant in the two intervention groups based on the Friedman test $(p<0.001)$. In the HBM group, before start of the intervention, $96.2 \%$ (sum of frequency of 1-3 times per week and 4-7 times per week) consumed imported rice, whereas after the 
intervention they diminished to $21.2 \%$, and three and six months after the intervention, the descending trend of imported rice consumption continued ( $20 \%$ and $16.3 \%$ respectively). In the ECO group, before the intervention, $70 \%$ of women (sum of frequency of 1-3 times per week and 4-7 times per week) consumed imported rice, which decreased to $2.5 \%$ three and six months after the intervention (from $6.3 \%$ immediately after the intervention). The reduction in the consumption of imported rice in both intervention groups was significant based on the Friedman test $(\mathrm{p}<0.001)$. In the HBM group, $1.2 \%$ of women (sum of frequency of 1-3 times per week and 4-7 times per week) consumed mixed rice before the intervention, but after the intervention this increased to $72.5 \%$, though in the third and sixth months after the intervention it showed a slight significant decrease $(66.3 \%)(\mathrm{p}<0.001)$. A total of $17.5 \%$ of women (sum of frequency of 1-3 times per week and 4-7 times per week) in the ECO group consumed mixed rice before the intervention, which after the intervention increased to $60.1 \%$, while during the third and sixth months after the intervention, a slight reduction was observed in the consumption of mixed rice. Consumption of mixed rice in the control group by the first, second, third, and fourth evaluations had no significant difference. The number of women in both intervention groups (HBM and ECO) who cooked rice as Pilaw showed a significant increase over time after intervention, and three and six months after the intervention compared with before intervention $(\mathrm{p}<0.001)$ (Table 5). Further, the results of Repeated measures analysis of variance after the intervention, three, and six months following the intervention showed that the three studied groups were significantly different in terms of consumption of local, imported, and mixed rice $(\mathrm{p}<0.05)$ (Figures 1-3).

Table 5. Comparison of consumption of local rice across three groups of HBM, ECO, and control over four measurement stages

\begin{tabular}{|c|c|c|c|c|c|c|c|c|c|c|c|c|c|c|c|c|}
\hline \multirow{2}{*}{\multicolumn{2}{|c|}{$\begin{array}{l}\begin{array}{l}\text { Frequency of } \\
\text { consumption }\end{array} \\
\end{array}$}} & \multicolumn{4}{|c|}{ HBM; Mean (SD) } & \multirow{2}{*}{ p- } & \multicolumn{4}{|c|}{ ECO; Mean (SD) } & \multirow{2}{*}{\begin{tabular}{|l}
$\mathrm{p}-$ \\
value
\end{tabular}} & \multicolumn{4}{|c|}{ CON; Mean (SD) } & \multirow{2}{*}{$\mid \begin{array}{l}\mathrm{p}- \\
\text { value }\end{array}$} \\
\hline & & $\mathrm{BI}$ & AI & $3 \mathrm{M}$ & $6 \mathrm{M}$ & & $\mathrm{BI}$ & $\mathrm{AI}$ & $3 \mathrm{M}$ & $6 \mathrm{M}$ & & BI & $\mathrm{AI}$ & $3 \mathrm{M}$ & $6 \mathrm{M}$ & \\
\hline \multirow[t]{3}{*}{$\begin{array}{l}\text { Local rice } \\
\text { (per week) }\end{array}$} & 0 & $78(97.5)$ & $75(93.8)$ & $69(86.3)$ & $65(81.3)$ & \multirow[t]{3}{*}{0.001} & $\begin{array}{l}170 \\
(87.5) \\
\end{array}$ & \begin{tabular}{|l|}
54 \\
$(67.5)$ \\
\end{tabular} & \begin{tabular}{|l}
50 \\
$(62.5)$ \\
\end{tabular} & \begin{tabular}{|l}
45 \\
$(56.3)$ \\
\end{tabular} & \multirow[t]{3}{*}{$<0.001$} & $\begin{array}{l}71 \\
(88.8)\end{array}$ & \begin{tabular}{|l|}
80 \\
$(100)$ \\
\end{tabular} & \begin{tabular}{|l|}
79 \\
$(98.8)$ \\
\end{tabular} & \begin{tabular}{|l}
80 \\
$(100)$ \\
\end{tabular} & \multirow[t]{3}{*}{$<0.001$} \\
\hline & $1-3$ & $0(0)$ & $4(5)$ & $9(11.3)$ & $12(15)$ & & $4(5)$ & $\begin{array}{l}22 \\
(27.5)\end{array}$ & $24(30)$ & $\begin{array}{l}6 \\
(32.5) \\
\end{array}$ & & $2(2.5)$ & $0(0)$ & $1(1.2)$ & $0(0)$ & \\
\hline & $4-7$ & $2(2.5)$ & $1(1.2)$ & $2(2.4)$ & $3(3.7)$ & & $6(7.5)$ & $5(6.2)$ & $6(7.5)$ & $9(11.2)$ & & $7(8.7)$ & $0(0)$ & $0(0)$ & $0(0)$ & \\
\hline \multirow[t]{3}{*}{$\begin{array}{l}\text { Imported } \\
\text { rice }\end{array}$} & 0 & $3(3.8)$ & $63(78.8)$ & $64(80)$ & $67(83.7)$ & \multirow[t]{3}{*}{$<0.001$} & $124(30)$ & \begin{tabular}{|l}
75 \\
$(93.8)$ \\
\end{tabular} & $\begin{array}{l}78 \\
(97.5) \\
\end{array}$ & \begin{tabular}{|l}
78 \\
$(97.5)$
\end{tabular} & \multirow[t]{3}{*}{$<0.001$} & $28(35)$ & $8(10)$ & \begin{tabular}{|l|}
13 \\
$(16.3)$ \\
\end{tabular} & \begin{tabular}{|l}
13 \\
$(16.3)$
\end{tabular} & \multirow[t]{3}{*}{$<0.001$} \\
\hline & $1-3$ & $26(32.5)$ & $12(15)$ & $9(11.3)$ & $5(6.3)$ & & \multirow{2}{*}{\begin{tabular}{|l|}
14 \\
$(17.5)$ \\
42 \\
$(52.5)$ \\
\end{tabular}} & $3(3.8)$ & $1(1.25)$ & $1(1.25)$ & & \begin{tabular}{|l|}
23 \\
$(28.8)$ \\
\end{tabular} & $\begin{array}{l}11 \\
(13.8)\end{array}$ & $\begin{array}{l}11 \\
(13.8)\end{array}$ & $\begin{array}{l}25 \\
(31.3)\end{array}$ & \\
\hline & $4-7$ & $51(63.7)$ & $5(6.2)$ & $7(8.7)$ & $8(10)$ & & & $2(2.5)$ & $1(1.25)$ & $1(1.25)$ & & \begin{tabular}{|l|}
29 \\
$(36.3)$ \\
\end{tabular} & $\begin{array}{l}61 \\
(76.3) \\
\end{array}$ & $56(70)$ & \begin{tabular}{|l}
42 \\
$(52.5)$
\end{tabular} & \\
\hline \multirow[t]{3}{*}{ Mixed rice } & 0 & 79 (98.8) & $22(27.5)$ & $27(33.7)$ & $27(33.7)$ & \multirow[t]{3}{*}{$<0.001$} & $\begin{aligned} 66 \\
(82.5)\end{aligned}$ & $32(40)$ & $32(40)$ & \begin{tabular}{|l}
38 \\
$(47.5)$
\end{tabular} & \multirow[t]{3}{*}{$<0.001$} & $\mid \begin{array}{l}61 \\
(76.3) \\
\end{array}$ & $72(90)$ & $68(85)$ & \begin{tabular}{|l}
67 \\
$(83.8)$
\end{tabular} & \multirow[t]{3}{*}{0.156} \\
\hline & $1-3$ & $0(0)$ & $43(53.8)$ & $34(42.5)$ & $34(42.5)$ & & $3(3.8)$ & $\begin{array}{l}41 \\
(51.3)\end{array}$ & $\begin{array}{l}38 \\
(47.5)\end{array}$ & $\begin{array}{l}31 \\
(38.8)\end{array}$ & & $6(7.5)$ & $1(1.2)$ & $1(1.2)$ & $4(5)$ & \\
\hline & $4-7$ & $1(1.2)$ & $15(18.7)$ & $19(23.8)$ & $19(23.8)$ & & $\begin{array}{l}11 \\
(13.7) \\
\end{array}$ & $7(8.8)$ & \begin{tabular}{|l}
10 \\
$(12.5)$ \\
\end{tabular} & \begin{tabular}{|l}
11 \\
$(13.8)$ \\
\end{tabular} & & $\begin{array}{l}13 \\
(16.3)\end{array}$ & $7(8.7)$ & $\begin{array}{l}11 \\
(13.8) \\
\end{array}$ & $\begin{array}{l}9 \\
(11.2) \\
\end{array}$ & \\
\hline \multirow[t]{2}{*}{$\begin{array}{l}\text { Cooking } \\
\text { method }\end{array}$} & Kateh & $70(87.5)$ & $18(22.5)$ & $3(3.7)$ & $0(0)$ & \multirow[t]{2}{*}{$<0.001$} & $\begin{array}{l}19 \\
(23.8)\end{array}$ & $8(10)$ & $5(6.2)$ & $4(5)$ & \multirow[t]{2}{*}{$<0.001$} & $7(8.8)$ & $\begin{array}{l}14 \\
(17.5)\end{array}$ & $24(30)$ & $\begin{array}{l}19 \\
(23.8)\end{array}$ & \multirow[t]{2}{*}{0.005} \\
\hline & Pilaw & $10(12.5)$ & $62(77.5)$ & $77(96.3)$ & $80(100)$ & & \begin{tabular}{|l}
61 \\
$(76.2)$
\end{tabular} & $72(90)$ & $\begin{array}{l}75 \\
(93.8)\end{array}$ & $76(95)$ & & \begin{tabular}{|l}
73 \\
$(91.2)$
\end{tabular} & $\begin{array}{l}66 \\
(82.5)\end{array}$ & $56(70)$ & $\begin{array}{l}61 \\
(76.2)\end{array}$ & \\
\hline
\end{tabular}

BI: Before intervention, AI: After intervention, 3M: Three months, 6M: Six months 


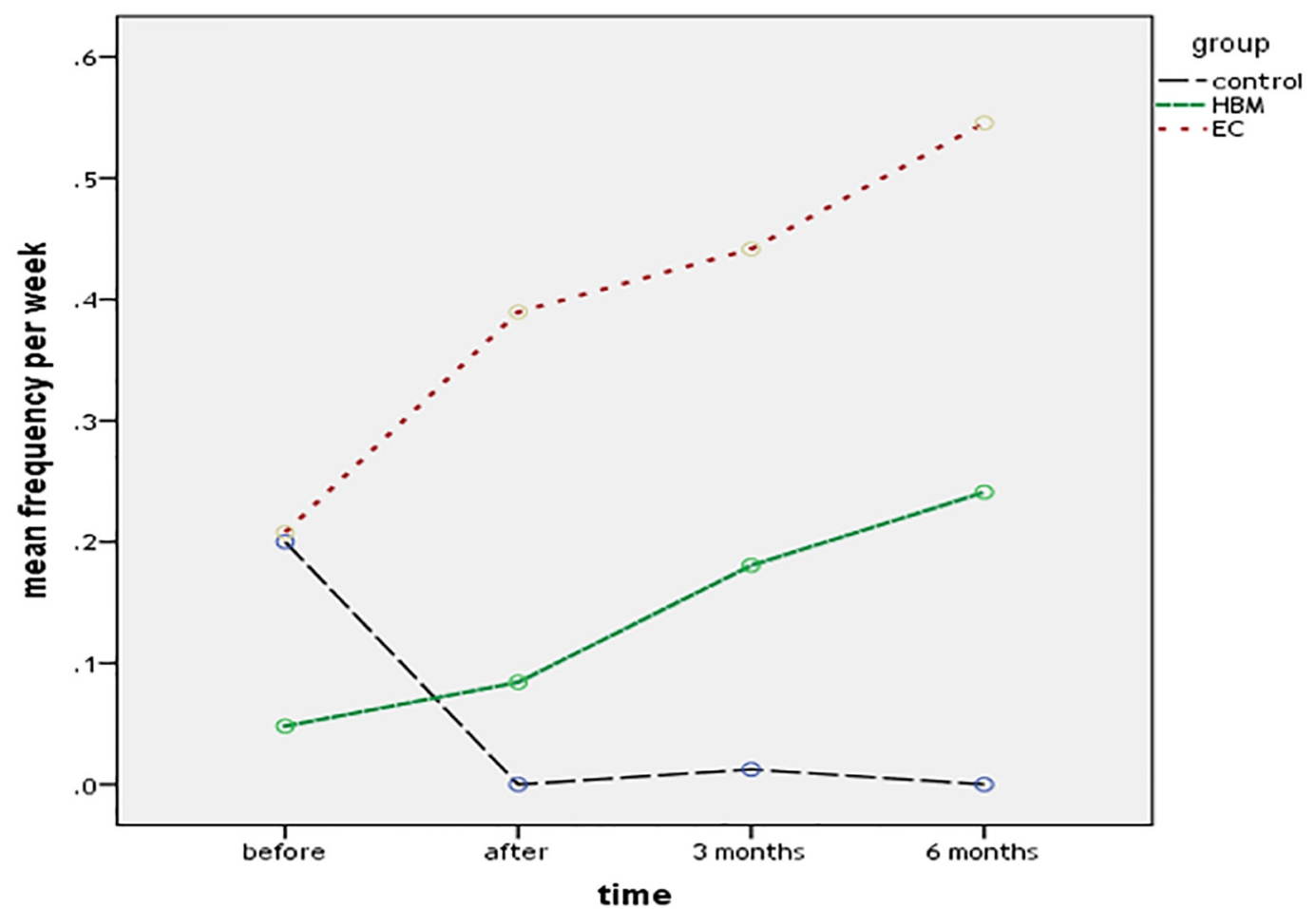

Figure 1. Comparison of consumption of local rice across three groups of HBM, ECO and control over four measurement stages

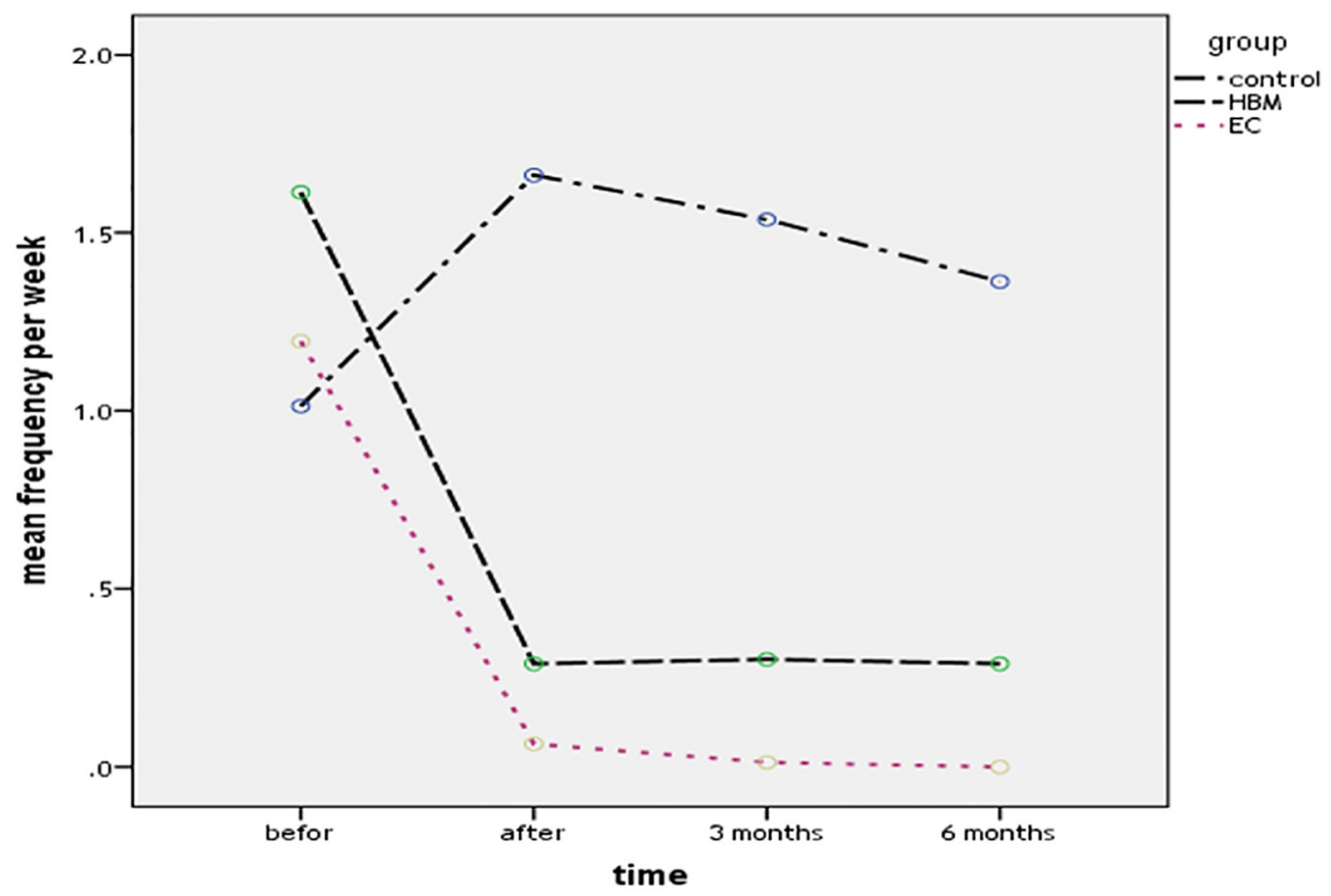

Figure 2. Comparison of consumption of imported rice across three groups of HBM, ECO and control over four measurement stages 


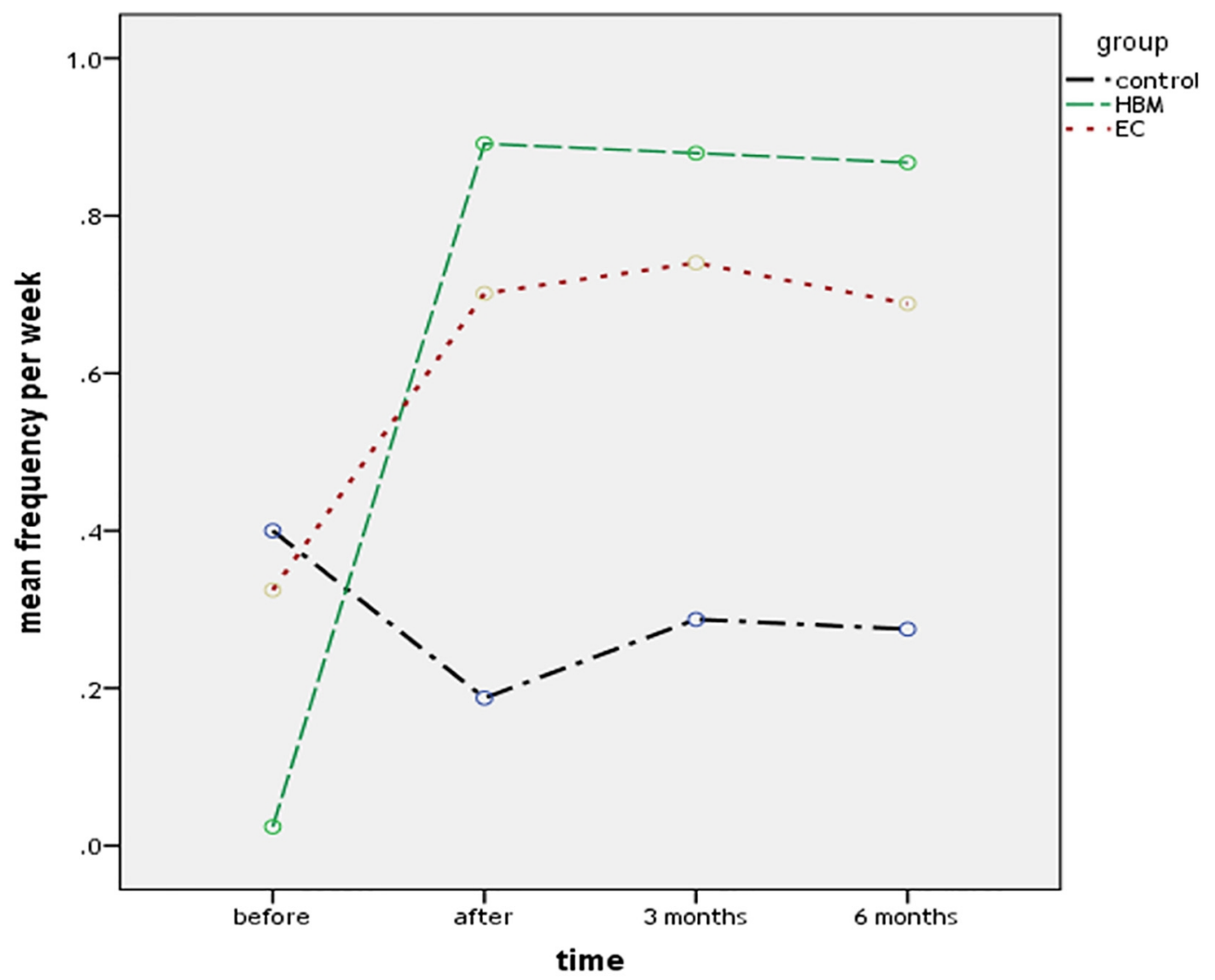

Figure 3. Comparison of consumption of mixed rice across three groups of HBM, ECO and control over four measurement stages

\section{Discussion}

This study was the first randomized controlled trial intervention program to compare the effect of two interventional models in the continuation of consumption of rice free from toxic metals in Iranian women and preventing people from developing diseases caused by consumption of rice contaminated with toxic metals. The findings of the research showed a significant improvement in the knowledge of participants about toxic metals and their effects on the body in the intervention groups after the intervention, in comparison with the period before the intervention and six months following completion of the intervention in comparison with the control group. This improvement was more durable in the ECO group than in the HBM group over the six months after the intervention. The results of a 2012 research by Ghaffari et al. were similar to those of the previous research in enhancing the nutritional knowledge following intervention in comparison with the period before it and reduction in the follow-up stage (23). Although the control group had a slight increase in knowledge about toxic metals by the second evaluations in comparison with the first evaluation, continuation of this knowledge showed a decrease by the third and fourth evaluations. However, there was a significant difference in the knowledge of people across the intervention groups with the control group. In this study, HBM intervention indicated significant positive changes in the model's constructs in comparison with the women in the control group after the intervention along with three and six months following completion of the intervention in comparison with the period before it. In the control group, the constructs of perceived seriousness, perceived benefits, and perceived barriers by the second, third, and fourth evaluations showed no significant difference in relation to the preliminary evaluation, while the constructs of perceived sensitivity and self-efficacy by the second evaluations showed a descending trend in relation to the first evaluation and during the six months. In the intervention group, our work was similar to a 2012 research by Ghaffari et al., in elevation of perceived sensitivity, perceived seriousness, perceived benefits after the intervention and follow-up in comparison with the period before the intervention (23), as well as a 2015 research by Wang et al., in continuation of the reduction in the perceived barriers after the intervention and until six months after its completion (24). The results of the educational intervention program suggested improved social support in the ECO group in relation to the control group after the educational intervention in relation to the period before the intervention and continued 
growth of social support after six months following completion of the intervention. These results were similar to the 2012 findings by Thorsen et al., done at worksite and the positive role of development of social network and enhancement of social support in having people follow a healthy diet and continuation of foods free from toxic metals (14). On the other hand, social support in the control group had a significant decline by the second evaluation and over the six months of evaluation. However, the change in social support in the 2015 research by Wang et al., was not significant over time (24). The women in the HBM group consumed local rice more than the control group in response to perceived sensitivity and seriousness, perceived benefits, and greater self-efficacy, with less perceived barriers after the intervention, three, and six months after the intervention in comparison with the period before the intervention. The women in the ECO group also consumed local rice more than the control group in response to greater social support after the intervention, and three, and six months after the intervention, in comparison with the period before the intervention. In addition, the ascending trend of cooking rice as Pilaw and its continuation during six months after the intervention were observed in both HBM and ECO intervention groups. It was assumed that the intervention based on the interpersonal model (ECO group) would have a greater effect in the continuation of consumption of rice free from toxic metals during six months following completion of the intervention, when compared with individual-based (HBM group) intervention. Therefore, evaluation of the change in the frequency of consumption of local rice and its substitution with imported rice following the intervention were considered as the consequence of the interventional program after the intervention in comparison with the period before the intervention and six months following completion of the intervention. The results of this research suggest a significant improvement in both intervention groups HBM and ECO considering consumption of local rice following the intervention in comparison with the period before it and its continuation six months after the intervention. However, the control group consumed no local rice after the intervention. Supporting the hypothesis of the study, development of consumption of local rice and its continuation after six months following completion of the intervention were greater in the ECO group than in the HBM group, when compared with the period before the intervention. Women in ECO group consumed local rice 27.5\% more than the HBM group. The number of women consuming imported rice after the intervention, three, and six months following the intervention in comparison with the period before it, showed a descending trend in both HBM and ECO groups, where reduction of consumption of imported rice was greater in the women of the ECO group than those in the HBM group. Consumption of imported rice in the control group by the second evaluation had an ascending trend in comparison with the first evaluation, and continued during the three and six months. On the other hand, the number of women consuming mixed rice after the intervention, and three, and six months following the intervention had a descending trend when compared with the period before the intervention in both HBM and ECO groups. However, the HBM group consumed more mixed rice than the ECO group following the intervention, and three, and six months after the intervention. In other words, this educational program resulted in a greater reduction of consumption of imported rice and increased consumption of local rice in the ECO group in comparison with the HBM group and the continuation of its consumption six months following completion of the intervention. Moreover, these results were similar to previous findings considering the effect of the HBM model and its continuation up to six months following the intervention (24) and the effect of the ECO model in improving a healthy diet and its continuation (14). The factor that probably gave rise to greater success of the educational program in selection of rice free from toxic metals and continuation of its consumption in the ECO group in comparison to the HBM group was the development of social support over the course of the intervention and the continuation of its development for six months following the intervention, i.e. development of the social network over time. Though, this change in the performance and its continuation may have been due to sharing experiences, group learning, and development of social network during six months after the intervention in this intervention group.

\section{Limitation}

This research had the following limitations: 1) evaluation of the performance of rice consumption was recognized in terms of the frequency of the number of women consuming rice. More accurate evaluation in terms of the amount of rice consumption (per $\mathrm{kg}$ ) is required by individual rice type; 2) due to the necessity of developing social networks in the ECO group and the region's cultural context, it was not possible to hold training sessions in the homes of participants. Thus, the individuals selected in organizations had higher academic degrees, which influenced the extent of participants' knowledge. Therefore, equalization of individuals in terms of academic studies is required before the intervention.

\section{Conclusions}

Nevertheless, due to development through giving knowledge to people in regard to selection of healthy foods, both intervention methods gave rise to continuation of consumption of rice free from toxic metals and reduction of 
consumption of rice contaminated with toxic metals. In changing the cooking manner from Kateh to Pilaw, they also had a positive effect. Development of social support six months following the intervention might have had a more effective role in improving the diet of people and continuing consumption of rice free from toxic metals. This study was the first evidence of comparing the effect of two society-based and individual-based intervention programs in continuation of consumption of foods free from environmental contaminants including toxic metals by considering the aspect of the effect of social support. Therefore, one of the solutions required for better improvement of nutritional performance and modifying diet and continuing consumption of foods free from toxic metals is to develop social support in other environmental intervention programs in the future.

\section{Acknowledgments:}

This paper was a result of a thesis called "investigation of the effect of interventions based on Health Belief Model and Ecological-Social frameworks on consumption of rice contaminated with toxic metals" for a PhD by research associated with Ms. Leili Shafiei approved in Kurdistan University of Medical Sciences.

\section{Conflict of Interest:}

There is no conflict of interest to be declared.

Authors' contributions:

All authors contributed to this project and article equally. All authors read and approved the final manuscript.

\section{References:}

1) Zazouli MA, Shokrzadeh M, Izanloo H, Fathi S. Cadmium content in rice and its daily intake in Ghaemshahr region of Iran. Afr J Biotechnol. 2008; 7(20): 3686-9.

2) Falahi E, Hedaiati R, Ghiasvand AR. Survey of iron, zinc, calcium, copper, lead and cadmium in rice samples grown in Iran. Food Addit Contam Part B Surveill. 2010; 3(2): 80-3. doi: 10.1080/19440041003671288. PMID: 24785496.

3) Morekian R, Mirlohi M, Azadbakht L, Maracy MR. Heavy metal distribution frequency in Iranian and imported rice varieties marketed in central Iran, Yazd, 2012. Int J Environ Health Eng. 2013; 2(1): 1 -5. doi: 10.4103/2277-9183.122419.

4) Järup L. Hazards of heavy metal contamination. British Med Bulletin. 2003; 68(1): 167-82. PMID: 14757716.

5) Glanz K, Mullis RM. Environmental Interventions to promote Healthy Eating. Health Educ Q. 1988; 15(4): 395-415. PMID: 3068206.

6) Shafiei L, Taymoori P, Yazdanshenas K. Awareness and attitude assessment regarding toxic metalcontaminated rice based on the Health Belief Model. J Adv Environ Health Res. 2016; 4(2): 78-87.

7) Sethares KA, Elliot K. The effect of a tailored message intervention on heart failure readmission rates, quality of life, and benefit and barrier beliefs in persons with heart failure. Heart Lung. 2004; 33(4): 24960. doi: 10.1016/j.hrtlng.2004.03.005. PMID: 15252415.

8) Zareban I, Niknami SH, Hidarnia A, Rakhshani F, Shahrakipour M, Moshki M. The effect of education based on health belief model on reduction of HbAlc level in diabetes type 2. Social Dev \& Health Promo. 2013; 3(2): 370-8.

9) Vehei H, Taghdisi M, Saidi M. Application of the health belief model for osteoporosis prevention among middle school girl students, Garmsar, Iran. Educ Health J. 2007; 20(1): 1-11.

10) Glanz K, Rimer K B, Viswanath K. Health Behavior and Health Education. Theory, Research and Practice: The Health Belief Model. United States of America: Jossey-Bass; 2008.

11) Graham DJ, Pelletier JE, Neumark-Sztainer D, Lust K, Laska MN. Perceived Social-Ecological Factors Associated with Fruit and Vegetable Purchasing, Preparation, and Consumption among Young Adults. J Acad Nutr Diet. 2013; 113(10): 1366-74. doi: 10.1016/j.jand.2013.06.348. PMID: 23958116.

12) Bandoni DH, Sarno FV, Jaime PC. Impact of an intervention on the availability and consumption of fruits and vegetables in the workplace. Public Health Nutr. 2010; 14(6): 975-81. doi: 10.1017/S1368980010003460.

13) Sorensen G, Linnan L, Hunt K. Worksite-based research and initiatives to increase fruit and vegetable consumption. Prev Med. 2004; 39: S94-100. doi: 10.1016/j.ypmed.2003.12.020. PMID: 15313078.

14) Thorsen AV, Lassen AD, Tetens I, Hels O, Mikkelsen BE. Long-term sustainability of a worksite canteen intervention of serving more fruit and vegetables. Public Health Nutr. 2010; 13(10): 1647-52. doi: 10.1017/S1368980010001242. PMID: 20444314. 
15) Israel B. Social networks and social support: implications for natural helper and community level interventions. Health Educ Q. 1985; 12(1): 65-80. doi: 10.1177/109019818501200106. PMID: 3980242.

16) Andajani-Sutjahjo S, Ball K, Warren N, Inglis V, Crawford D. Perceived personal, social and environmental barriers to weight maintenance among young women: A community survey. Int J Behav Nutr Phys Act. 2004; 1(15): 1-15. doi: 10.1186/1479-5868-1-15. PMID: 15462679, PMCID: PMC524367.

17) Amiri P, Ghofranipour F, Ahmadi F, Hosseinpanah F, Montazeri A, Jalali-Farahani S, et al. Barriers to a healthy lifestyle among obese adolescents: a qualitive stuady from Iran. Int J Public Health. 2011; 56(2): 181-9. doi: 10.1007/s00038-010-0119-6.

18) Pomerleau J, Lock K, Knai C, McKee M. Interventions designed to increase adult fruit and vegetable intake can be effective: a systematic review of the literature. J Nutr. 2005; 135(10): 2486-2495. PMID: 16177217.

19) Fuemmeler B, Masse LC, Yaroch A, Resnicow K, Campbell MK, Carr C, et al. Psychosocial mediation of fruit and vegetable consumption in the body and soul effectiveness trial. Health Psychol. 2006; 25: 474-83. doi: 10.1037/0278-6133.25.4.474. PMID: 16846322.

20) Evans GL, McNeil LH, Laufman L. Determinants of Low-fat Eating Behaviors among Midlife African American Women. J Nutr Educ Behav. 2009; 41(5): 327-33. doi: 10.1016/j.jneb.2008.07.006. PMID: 19717115.

21) Alidosti M, Sharifirad GR, Golshiri P, Azadbakht L, Hasanzadeh A, Hemati Z. An investigation on the effect of gastric cancer education based on Health Belief Model on knowledge, attitude and nutritional practice of housewives. Iran J Nurs Midwifery Res. 2012; 17(4): 256-62.

22) Zazouli MA, Mohseni Bandpei A, Ebrahimi M, Izanloo H. Investigation of Cadmium and Lead Contents in Iranian Rice Cultivated in Babol Region. Asian J Chem .2010; 22(2):1369-76.

23) Ghaffari M, Tavassoli E, Esmaillzadeh A, Hassanzadeh A. Effect of Health Belief Model based intervention on promoting nutritional behaviors about osteoporosis prevention among students of female middle schools in Isfahan, Iran. J Educ Health Promot. 2012; 1(14): 1-4. doi: 10.4103/2277-9531.98572. PMID: 23555117, PMCID: PMC3577402.

24) Wang J, Ye L, Zheng Y, Burke LE. Impact of Perceived Barriers to Healthy Eating on Diet and Weight in a 24-Month Behavioral Weight Loss Trial. J Nutr Educ Behav. 2015; 47(5): 1-5. doi: 10.1016/j.jneb.2015.05.004. PMID: 26162481, PMCID: PMC4761236. 